\title{
Responding to Rivals and Complements: How Market Concentration Shapes Generational Product Innovation Strategy
}

\author{
Scott F. Turner \\ Moore School of Business, University of South Carolina, Columbia, South Carolina 29208, \\ scott.turner@moore.sc.edu \\ Will Mitchell \\ The Fuqua School of Business, Duke University, Durham, North Carolina 27708, will.mitchell@duke.edu
}

Richard A. Bettis

Kenan-Flagler Business School, University of North Carolina at Chapel Hill

Chapel Hill, North Carolina 27599, r_bettis@unc.edu

\begin{abstract}
$T^{3}$ his study examines how competitive market conditions shape the responsiveness with which businesses release generational product innovations (GPIs) following the introduction of GPIs by either competitors or complementary firms. GPIs are substantial technical advances in the performance of products within technology regimes. Prior studies of innovation timing in the organizational strategy literature emphasize internally driven strategies of GPI. Although internally driven strategies may predominate when businesses face diffuse competition for their product lines, the literature largely overlooks the point that businesses need to be increasingly responsive to external events as market concentration increases. This study, which examines businesses competing in the U.S. packaged software industry in the 1990s, shows that increasing industry concentration raises the stakes surrounding market positions and leads to greater interdependence of innovation strategies in an industry-including interactions both with competitors and with other players in a larger system of complementary products. As concentration increases, therefore, organizations are less driven by historical patterns of innovation and become increasingly responsive to innovations by both types of external actors.
\end{abstract}

Key words: generational product innovation; innovation timing; complementary technologies; time-based pacing; competitive rivalry

History: Published online in Articles in Advance December 30, 2009.

Generational product innovations are substantial technical advances in the performance of products within technology regimes. This form of innovation, such as the introduction of motor vehicle model upgrades and successive generations of microprocessors, is common in many industries but is an under-studied element of innovation strategy (Lawless and Anderson 1996). The initial discussions of generational product innovation (GPI) in the organizational strategy literature have emphasized factors inside businesses (Brown and Eisenhardt 1997, 1998), with little attention to assessing external influences on GPI introduction. This exploratory study draws on several strands of the innovation studies literature to extend the emerging literature on GPI by examining how competitive and complementary technological events in the external environment influence the timing of GPI introductions. We focus on how market concentration shapes the responsiveness of businesses' GPI releases to the release of competitor and complementary innovations.

The innovation studies literature suggests that without impetus from particular external events, firms and the businesses within them tend towards internally driven product introduction strategies. This broad-based literature draws notably upon behavioral and routinesbased perspectives of organizations (Baum 1999, Brown and Eisenhardt 1995, Nelson and Winter 1982). In this stream of research, the time since the previous innovation is a central factor that shapes innovation releases. For instance, Amburgey et al. (1993) draw on the idea of organizational momentum to argue that interdependencies between organizational routines and innovation strongly influence the timing of innovation. This argument reflects the idea that introducing innovations is disruptive for internal operating routines (Barnett and Carroll 1995), yet routines for innovation themselves can atrophy as time passes (Argote 1999, Greve 2007). Similarly, scholars such as Gersick (1994), Brown and Eisenhardt (1997), and Sastry (1997) have argued that the opportunity to smooth out internal coordination activities may lead businesses to adopt time-based pacing, in which they seek to release product-line innovations at consistent points in calendar time (e.g., releasing 
GPIs every 24 months). Such temporal patterns reflect inertial forces associated with stable development and marketing routines, corresponding organizational efficiencies, and the role of routines in retaining organizational memory (Perrow 1970, Brown and Eisenhardt 1998, Nelson and Winter 1982).

Despite the incentives for internally driven innovation timing, most businesses operate in competitive markets in which external events in the competitive landscape sooner or later intrude on internal rhythms (Bettis and Hitt 1995, Lee et al. 2000). External events force businesses to adapt to competitors' actions and to advances in complementary technologies rather than to rely solely on internally driven patterns of innovation. We refer to GPI introduction strategies that respond to external competitive and complementary events as externally driven GPI strategy. Prior research has not examined the conditions under which external events override incentives for internally driven GPI strategy. This is an important element in the overall GPI strategy because mistakes in this transition are likely to engender competitive problems. We argue that externally driven GPI strategy becomes more significant as markets consolidate and strategies become more interdependent.

We investigate two external events that may trigger a firm's GPI: the introduction of innovations by competitors and the introduction of innovations in technologies that complement a core set of products. These events address two important domains for innovation strategy: the pattern of interactions with competitors and the pattern of interactions with other players within larger systems of complementary products and businesses. Competitor innovation has received some attention as a spur to innovation strategy in the economics of innovation literature and in studies of competitive rivalry (Lee et al. 2000, Reinganum 1989). Complementary innovation, meanwhile, has received little attention to date; indeed, the activities of businesses producing complementary products are underemphasized elements of industry dynamics (Brandenburger and Nalebuff 1997). We argue that the degree of concentration in the market influences the extent to which both of these types of external events spur the introduction of GPIs.

We study GPI strategies in the packaged software industry during the 1990s, focusing on four software application markets (computer-aided design, desktop publishing, spreadsheets, and word processing) and two operating system platforms (Windows ${ }^{\circledR}$ and Macintosh $\left.{ }^{\circledR}\right)$. The results support our argument that increasing market concentration raises the stakes surrounding market positions and leads to greater competitive interdependence in an industry, forcing businesses to undertake GPI strategies for their product lines that respond to competitive and complementary external events. The findings extend our understanding of market concentration and external coordination as important elements of innovation strategies and offer implications for the economics of innovation and competitive rivalry literatures as well as help advance the emerging literature in dynamic capabilities. This research seeks to establish a baseline model regarding the impact of market structure on the timing of GPI. Because GPI in general, let alone the timing of GPI, has received little research attention, our study has a substantive exploratory element. The results provide an initial foundation for our understanding and suggest several extensions and refinements that additional research could fruitfully examine.

\section{Conceptual Background}

This section develops three concepts that are central to the research: (1) generational product innovation, (2) strategies for innovation timing, and (3) market concentration. The first segment explains the concept of GPI and locates it within the innovation studies literature. The second segment outlines internally driven and externally driven strategies of innovation timing. This distinction is fundamental to the research because we seek to relate market concentration to preferences for these two strategies. The third segment introduces the concept of market concentration and briefly reviews key arguments regarding how it influences innovation strategy.

\section{Generational Product Innovation}

A GPI represents a substantial advance in the technical performance of an existing product within a technological regime, where a technological regime is a common set of scientific and technical principles that generate patterns of solutions for particular technological problems and support periods of cumulative advance along accepted technological trajectories (Dosi 1982, Nelson and Winter 1982). Hence a GPI provides a substantial improvement in product functionality (where products can be physical goods or nonphysical services) while drawing on an established set of technical principles. GPI commonly occurs within product lines (for simplicity, we will refer to the organizational unit that is responsible for a product line as a "business," although noting that some businesses may offer multiple product lines), which tend to draw on common pools of knowledge. For instance, consider applications software. In January 1994, Microsoft's spreadsheet business introduced Version 5.0, a GPI for its Excel ${ }^{\circledR}$ for Windows product line. Version 5.0 of Excel was a GPI because it provided substantial new features for graphing and charting as well as retrieving and manipulating data, which built on the industry's existing knowledge base in software design. Later that same year, in turn, the business introduced Version 5.0a of Excel. The release was not a GPI because it primarily refined existing functionality by correcting several automation and implementation problems 
that surfaced from the Excel 5.0 version release. Identifying the distinction between GPI and minor changes typically depends on criteria that are relevant to particular industry and technical settings. The empirical section of the paper uses a multidimensional approach to identifying GPIs that is appropriate in our analytic setting.

GPI can provide advances in functionality that range from refreshing a product line to substantially transforming product scope. In the auto industry, for example, regular model upgrades are often referred to as the refreshing of models. In consumer electronics, meanwhile, recent GPIs by Apple for the iPod $®$ have transformed this device from a mobile music source to a broader multimedia package (e.g., photographs, movies, and TV episodes) and integrated it with cellular phone technology (iPhone $\left.{ }^{\circledR}\right)$.

It is useful to position GPI within the innovation studies literature. This is a complex literature. Over time, different authors and fields have generated multiple typologies and categories of innovation (e.g., radical-incremental versus radical-modular-incrementalarchitectural versus disruptive-reinforcing versus onor off-trajectory versus evolutionary-transformative versus drastic or nondrastic versus encompassingcomplementary-incremental, among many alternatives). All of these typologies interrelate to a greater or lesser degree. Furthermore, innovation typologies by their nature break a multidimensional continuum of innovation into discrete categories, leaving ambiguity in the transition between categories. The important point is that GPI relates closely to what the literature often calls nondrastic, evolutionary, or incremental forms of innovation, which we examine further below, but with distinct aspects. In particular, the idea of substantial advance in functionality that draws from an established knowledge base (the core definition of GPI) does not fit neatly within traditional typologies. It is important to keep this point in mind in the following discussion.

Within the definitions of the economics of innovation literature, generational innovations are nondrastic innovations. Where the economics of innovation literature suggests that drastic innovations result in postinnovation monopolies for the innovating business, nondrastic innovations retain elements of the pre-innovation market structure (Gilbert and Newbery 1982, Baldwin and Scott 1987). In this sense, GPI is an evolutionary form of innovation (Dougherty 1992) that occurs under what Kuhn (1962) refers to as normal organizational and technological conditions. In the organizational concept of normality, GPI represents homeostatic change, which Huff et al. (1992) describe as an ongoing process of innovation conducted within an existing organizational context.

Although scholarly research directs most attention to drastic innovations, businesses in many industries commonly expend as much or more effort on nondrastic changes. As Scherer and Ross (1990, p. 642) point out, "most industries experience a continuous stream of innovations over time, and in many cases, each completed new product or process sets an agenda focusing improvement work for the next technological generation." GPI is a common form of nondrastic innovation (Brown and Eisenhardt 1997, Lawless and Anderson 1996), but few academic studies have addressed this aspect of technological change.

The primary reason for this disconnect is our earlier point that GPI does not fit neatly within traditional innovation categories, such as the longstanding incremental-radical distinction or more complex schema such as Henderson and Clark's (1990) radical-modulararchitectural-incremental categories. Hence although GPI reflects elements of broader conceptualizations (i.e., nondrastic, evolutionary, incremental), GPI has traveled largely under the radar of academic research. The core point is that GPI is an important phenomena that merits focused attention by scholars of technological change.

We develop the arguments about GPI at the level of the product line because the concept of generational product innovation relates to existing product lines and the organizational routines that support them. Our research question focuses on competitive conditions in the focal product market.

\section{Strategies for Innovation Timing: Internally Driven and Externally Driven}

The timing of innovation release is a critical element of product strategy (Reinganum 1989, Brown and Eisenhardt 1997). Businesses have strong incentives towards internally driven GPI strategies, and the time since previous innovation plays a central conceptual role in this strategy for innovation. Pacing the release of GPIs based on the passage of time between innovations enables organizations to balance the costs associated with the disruption of internal routines from innovation release with the costs of allowing a product to become stagnant in the marketplace. At the same time, the consistency of time-based pacing facilitates the development and coordination of stable internal routines (Nelson and Winter 1982, Winter 1987), permitting efficient resource allocations within and between organizational units (March and Simon 1958, Brown and Eisenhardt 1997). However, the control and stability of an internally driven innovation strategy may ignore or only partially account for the resolution of technological uncertainties in the industry. Seldom can a single business dominate or even maintain pace within an industry exclusively through an internally driven innovation strategy; instead, as the industry evolves, external factors eventually must play important roles for all competitors.

By contrast with internally driven innovation strategies, externally driven innovation represents a strategy in which businesses release GPIs in response to events in 
the competitive marketplace. The innovation studies literature directs particular attention to competitor innovations as events that will be relevant for GPI strategy (Lee et al. 2000, Reinganum 1989) and hints at a second type of relevant event in the form of complementary innovations (Klevorick et al. 1995, Teece 1986). Competitor innovation events center on interdependence in the form of innovation rivalry among competing products (Beath et al. 1995). By contrast, complementary innovations focus on the interdependence among technologies within larger systems (Dosi 1988, Brandenburger and Nalebuff 1997). Whereas competitor innovation represents a direct form of interdependence, complementary innovation represents an indirect form of interdependence in which businesses compete to align themselves with supporting technologies (e.g., the alignment of packaged software with changes in operating systems, or vehicle design with advances in highway technology). The implications of both forms of interdependence for industry dynamics suggest that these events will often trigger GPI responses.

\section{Market Concentration}

Market concentration is a function of the number of products in a market and their respective shares of total sales. The more concentrated an industry, the larger the share of production that tends to consolidate in the hands of a smaller set of businesses. Economic arguments raise alternative views on concentration and innovation. Scholars in the Schumpeterian tradition argue that increasing concentration provides businesses with greater opportunity to appropriate the returns of their investments in innovation, including greater price control, and posit that concentration facilitates innovation (Scherer 1992, Schumpeter 1950). In fact, Kamien and Schwartz (1982, p. 84) note that this idea represents "the heart of Schumpeterian theory." However, industrial organization economists also argue that as concentration increases, businesses face less competitive pressure to stimulate innovation of their goods and services (Curry and George 1983, Scherer and Ross 1990). Empirically, studies have found mixed relationships between concentration and innovation. Indeed, Cohen's (1995) expansive review of this empirical research concluded that concentration has little direct effect on innovation.

Reflecting on the mixed results in prior work, Cohen (1995) suggested that an understudied area for innovation research lies at the intersection of industry conditions and organization activities. Concentration may have such a contingent effect, in which its major influences on innovation strategy arise in combination with other factors, such as external competitive and complementary events. This study examines such contingencies by investigating the effect of market concentration on the responsiveness of innovation to these external events in the context of GPI.

\section{Hypotheses}

The need to understand external drivers of innovation strategy is important in many different industries, such as automobiles, consumer electronics, and software. Market concentration is likely to shape the impact of two types of external events-the release of competitor and complementary innovations - that reflect patterns of interactions with competitors and other players in larger market contexts.

We assume that businesses have incentives to release GPIs in their product lines, even in concentrated markets. As a point of reference, an oligopolistic theory of competition suggests that competitors would avoid innovation, attempting to jointly maximize profits by eliminating the costs associated with this form of innovation. Yet economics of innovation scholars argue that traditional oligopoly theory, with roots in pricing, faces challenges in explaining innovation behavior (Scherer and Ross 1990). These challenges lend support to our assumption of incentives to innovate for three reasons. First, in order to maximize joint profits, all players must restrict innovation, but such coordination is difficult to maintain given the threat that at least one player conceals its investment in innovation and, by cheating, overtakes the market (Baumol 2002). Second, innovation-avoidance strategies suit static markets in which innovations only affect the allocation of market shares. However, many generational innovations, such as new automotive models and software upgrades, stimulate market growth as businesses compete for new customers (Scherer 1984). Third, even within relatively static markets, incumbents have incentives to introduce GPIs in order to dissuade new market entrants, a situation analogous to limit pricing (Schumpeter 1950, p. 90).

We begin by considering the logic for internally driven innovation strategy, with a baseline expectation that the likelihood of releasing a GPI will have a curvilinear, inverse-U relationship with time since previous innovation. We expect that in the initial stages following an innovation release, organizations are less likely to introduce a GPI. The delay occurs because there is little incentive to revisit the corresponding disruption of operating routines associated with introducing a new generation, while the product innovation represents a recent introduction in the marketplace (Barnett and Carroll 1995, Nelson and Winter 1982, Hannan and Freeman 1989). As the time since previous innovation increases, though, the product in the market becomes increasingly out of date and the incentives for releasing a GPI increase.

However, we expect that rather than continually increasing in likelihood, the likelihood of GPI introduction will eventually decline, producing a nonmonotonic relationship with time since prior introduction. The decline reflects eventual decay of organizational routines (Kelly and Amburgey 1991, Miller and Friesen 1980). 
Following behavioral theory, organizations search for solutions, such as product innovation, in the neighborhood of their most recently enacted routines (Cyert and March 1963). Eventually, however, unused routines begin to decay (Amburgey et al. 1993). It follows that as time since previous innovation increases beyond a threshold, the routines that are involved in GPI increasingly atrophy through lack of use (Argote 1999, Greve 2007).

The above logic for a nonmonotonic relationship draws from research in organizational ecology that examines the disruptive and dynamic effects of prior changes (Baum 1999). Further, this pattern is consistent with arguments from the time-pacing literature suggesting that consistently introducing GPI releases across time enables the development and coordination of stable internal routines, which permit efficient resource allocations within organizations (Bluedorn 2002, Brown and Eisenhardt 1997). Thus the logic of internally driven innovation strategy suggests an inverse-U-shaped relationship between the time since previous innovation and the likelihood of releasing a GPI.

Hypothesis 1A (H1A). The likelihood that a business will introduce a generational product innovation will have an inverse- $U$ relationship with the time since its previous innovation in a given product line.

The incentives for an internally driven strategy for GPI focus largely on minimizing the disruptions and coordination costs associated with developing and introducing innovations (Barnett and Carroll 1995, Brown and Eisenhardt 1997). As market concentration increases, however, a strategy of simply releasing innovations according to internal rhythms faces increased risks. Indeed, in the face of strong competitors, adaptation becomes more important because the stakes associated with existing market positions increase (Somaya 2003). Specifically, the product line faces greater potential losses of market share and, moreover, the market share at risk has greater profitability owing to the presence of market power in the industry (Bain 1951, Scherer and Ross 1990). Hence as markets consolidate, organizations' strategic choices will decreasingly be driven by concerns about internal disruption of routines related to innovation as businesses pay more attention to competitive conditions that affect their products. Although internal forces may still produce a nonmonotonic relationship with time since previous innovation, that relationship will be flatter in more concentrated markets. Thus we expect that as market concentration increases, the inverse-U-shaped relationship between time since previous innovation and the likelihood of releasing a GPI will diminish.

HyPoTHESIS 1B (H1B). The greater the market concentration, the flatter the relationship between time since previous innovation and the likelihood a business will introduce a generational product innovation.
Next we consider the responsiveness of GPI to competitor innovation events. As a baseline, organizations have incentives to respond to GPIs by marketplace rivals; otherwise, they may sacrifice profit opportunities, cede market share, and face heightened survival pressure (Lee et al. 2000, Smith et al. 2001). Although responses to rival innovations may take multiple forms, we focus on matching responses (i.e., responding to generational innovation with generational innovation). This approach is consistent with the game theory literature on innovation from economics (Reinganum 1989, Baldwin and Scott 1987) and the competitive rivalry literature from strategic management (Smith et al. 1991).

We expect a positive relationship between market concentration and response to competitor GPI. Although economic theories direct attention to pricing interdependencies in concentrated markets, less attention has been directed to the impact of concentration on innovation rivalry (Grabowski and Baxter 1973, Cohen 1995). As nondrastic innovations, GPIs do not result in post-innovation monopoly conditions; instead the market structure following the innovation release retains elements of the pre-innovation structure (Baldwin and Scott 1987, Gilbert and Newbery 1982). As such, we expect market concentration to increase the incentives to respond to competitors.

As market concentration increases, the stakes associated with existing market positions increase (Bain 1951, Kamien and Schwartz 1982, Somaya 2003). At high market concentration, greater market share is typically allocated across fewer products. Therefore, each product in the market faces a greater risk of losing market share in response to GPI releases by competitors. Further, in concentrated markets, organizations have greater power for setting prices and realize greater profitability (Bain 1951, Scherer and Ross 1990). Therefore, as market concentration increases, businesses stand to lose more in terms of product profitability. In sum, with greater streams of rents at stake, we expect greater responsiveness to competitors' GPIs.

HYPOTHESIS $2(\mathrm{H} 2)$. The greater the market concentration, the greater the likelihood of generational product innovation in response to the release of a generational product innovation by a competitor.

Next we address responsiveness to complementary innovation events. The value of many products is influenced by their interdependence with complementary technologies (Stieglitz and Heine 2007, Teece 1986). Consider microcomputing systems, in which the value of applications software depends on complementary technologies such as operating systems and microprocessors. Complements exist within a variety of systems, including telecommunication networks (Davies 1996), industrial ecosystems (Desrochers 2002), and surgical units (Edmondson et al. 2001). 
As a baseline, organizations have incentives to release GPIs in response to complementary innovations. The release of complementary innovations provides new technological opportunities, which increase the likelihood of successful innovation for any given amount invested in the search process (Breschi et al. 2000, Klevorick et al. 1995). Expansion in the interstate highway system in the United States during the 1950s, for example, increased incentives for generational vehicle innovations suited to longer distances and higher speeds. Similarly, advances in biomechanics science and the technology of anthropomorphic devices (i.e., crash test dummies) have increased incentives for automotive manufacturers to invest in generational vehicle innovations related to passenger safety.

In turn, advances in technological opportunity stemming from complementary innovations affect competitive dynamics. The stability of incumbent market positions is partly a function of the distance between the technological potential for a product and the state of technological advance realized in incumbent products. Thus complementary innovations reduce the stability of market positions (Kamien and Schwartz 1982) by providing new technological opportunities (i.e., increasing the distance between technological potential and realized product technology), which cause corresponding reductions in entry barriers and increased competitive threat to incumbents by potential market entrants (Utterback 1996, Hartman et al. 1993). Therefore, incumbents have incentives to innovate in order to preempt or match challenges from potential entrants.

The core point here is that as market concentration increases, there is greater risk of loss of market share for incumbents, and the market share at risk tends to be more profitable than would be expected in more fragmented market conditions. Therefore, there is greater potential loss for incumbents if competitors gain preemptive advantages, so organizations are more likely to respond to the challenges associated with complementary innovation releases.

Hypothesis $3(\mathrm{H} 3)$. The greater the market concentration, the greater the likelihood of generational product innovation in response to the release of a generational product innovation in a complementary technology.

In summary, as market concentration increases, we expect GPI to become less reflective of historical timebased patterns of innovation (i.e., a flatter relationship with time since previous innovation) and increasingly responsive to external events. Within the external environment, we expect greater responsiveness to reflect both competitor innovation and complementary innovation as key influences on GPI strategy. Figure 1 summarizes the conceptual arguments concerning the relationship between time since previous innovation, external innovation events, market concentration, and GPI releases.
Figure 1 Conceptual Model of Generational Product Innovation Release

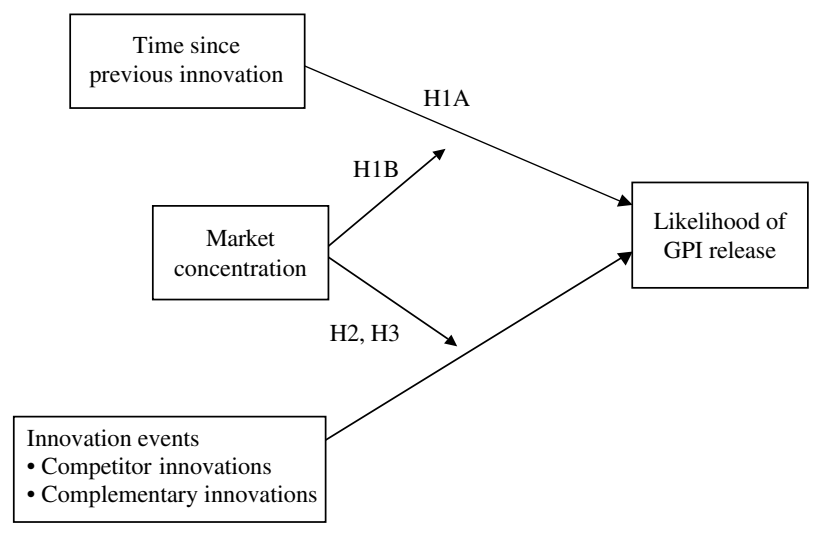

\section{Data and Methods}

\section{Data}

Our analysis focuses on business productivity software products in the United States from 1994 to 1998 . We considered organizations competing in four market segments: computer-aided design (CAD), desktop publishing, spreadsheets, and word processing. Primary sources included market research data and industry trade publications. PC Data, a market research firm that specialized in the computing industry, supplied us with monthly product sales data for the four market segments. Product data came from standalone product sales (sales of integrated software packages were low during the study period). PC Data informed us that its data represent the following annual percentages of the U.S. retail software market in each year from 1994 to 1998: 33\%, 60\%, 70\%, $80 \%$, and $80 \%$.

We used multiple secondary sources to gather baseline data, such as cumulative innovations in the industry, covering the life span of all the products in our data set. Our historical starting point was 1981, the year in which IBM introduced its personal computer. We conducted extensive searches across multiple information databases and industry trade publications (e.g., Factiva, InfoWorld) for the 1981 through 1998 period. We also searched company web pages and at times contacted companies directly to address areas of uncertainty.

We referenced product comparison reports in the trade press to segment products into competitively equivalent markets. We obtained data about four substantial segments, which the industry typically identifies by approximate list price ranges. The four segments include low-end CAD $(<\$ 1000)$, high-end desktop publishing (\$500-\$900), spreadsheets (\$100-\$600), and highend word processing (\$350-\$700). Representative products include TurboCAD ${ }^{\circledR}$, PageMaker ${ }^{\circledR}$, Excel, and WordPerfect ${ }^{\circledR}$.

Our examination considered products competing on the Macintosh and Windows operating platforms. We 
identified 35 software business lines across the two platforms and four market segments existing between 1994 and 1998. Almost all of the business lines were owned by different corporations, consistent with CampbellKelly's (2001, p. 110) historical account of the relatively low degree of diversification for most personal computer software producers, and did not experience ownership changes between 1994 and 1998. A few corporations in our sample operated in more than one of the business productivity markets in the study (from two to three corporations, depending on the year). In addition, a few product lines changed corporate ownership via business acquisitions during the study period; for example, Adobe took over the Framemaker desktop publishing line when it acquired Frame Technology, the original developer of the product, in 1995. We control for both multibusiness parents and change of corporate ownership in sensitivity analyses.

\section{Variables}

Table 1 and Table 2 present descriptive statistics.

Dependent Variable. Our focal dependent variable, generational product innovation (GenProdInnov), is a binary event with values equaling one for the month in which an organization released a GPI and zero otherwise. Between 1994 and 1998, 69 GPI events occurred across the 35 software business lines. The range of GPI releases per business line was 0-6 between 1994 and 1998. Our analysis focused at the product line level (e.g., Excel for Windows), which can be contrasted with the business unit level that may span multiple products (e.g., Excel, including both Windows- and Macintosh-based product lines) and the firm level (e.g., Microsoft). The product line level of analysis aligns with the central concepts in our arguments.

To identify GPIs, we determined whether an innovation release represented a significant advance in technical performance, relative to the existing product and within a technological regime. This required two related assessments. The first question was whether an innovation advance crossed the threshold into a new technological regime. We based this assessment on the operating system. For the Macintosh platform, there was no new technological regime within our empirical window. Alternatively, when DOS-centric organizations released their first Windows product, we viewed the event as crossing technological regimes and operationalized the event as a new market entry. As such, we considered any innovation releases with significant technical advance within an operating system platform as GPI releases.

The second assessment was to distinguish between generational innovations and minor "bug fix" releases. Although technical performance may improve in both cases, trade press accounts suggested that the significance of the advance was primarily corrective in the case of minor releases. In addition, the trade press did not publish many of the release dates for the minor innovations. To distinguish GPIs from minor innovation releases, we focused on the significance of the technical advance through the archival trade press. To obtain reliable classifications, we employed a triangulating, multiple-indicator approach that focused on three dimensions: (a) the number of feature additions and enhancements; (b) the numbering convention for the product innovation release (i.e., Version 1.2, 1.21, 2.0); and (c) the pricing schedule for the product innovation release (i.e., the upgrade list price relative to the full list price). Through our historical review of the trade press, we observed that the latter two indicators typically reflect substantial technical advances.

As a validity check, we discussed the concept and measurement of GPI with an industry expert who has extensive relevant experience in software development, market research, and a leading software trade association. He confirmed that GPI is a relevant distinction from minor innovation bug fixes. In addition, he agreed that the three dimensions (new features, numbering convention, and pricing schedule) are meaningful indicators of GPI. The appendix describes the reliability of the GPI classification system.

Focal Explanatory Variables. For internally driven innovation, we examined time since previous innovation to capture time-based influences on innovation introduction. Our measure is the elapsed calendar time since the prior innovation release for the product line. Prior release can be either the initial release of the product or the prior GPI release. TimeSinceInnov starts at one for the first month following an innovation release. This monthly clock then increments by one for each month until a subsequent innovation release, its removal from the market, or the end of our data panel.

For the competitive aspects of externally driven innovation, we identify the competition's release of GPI (CompetitionInnov) with a binary variable indicating whether any competing organizations released a GPI in the prior month. We employed the binary form because there were only three instances in which more than one competitor released a GPI in the same market segment and month. These instances were limited to the word processing and CAD segments for the Windows platform. We found materially equivalent results in sensitivity analyses that used the total number of competitor innovations in place of the binary indicator variable.

For the complementary elements of externally driven innovation, we examined two technological opportunity event variables: microprocessor innovation (TechOppMP) and operating system innovation (TechOppOS). For microprocessor innovation, Intel and Motorola were the dominant suppliers for the IBMcompatible and Macintosh systems in the 1994-1998 
Turner, Mitchell, and Bettis: How Market Concentration Shapes GPI Strategy

Table 1 Variable Summary Statistics and Product-Moment Correlations ( $N=2,041$ Organization-Months)

\begin{tabular}{|c|c|c|c|c|c|c|c|c|c|c|c|c|c|c|c|c|c|c|}
\hline Variable & Mean & StdDev & Min & & Max & 1 & 2 & 2 & 3 & 4 & 5 & 6 & 7 & 8 & 9 & 10 & 11 & 12 \\
\hline 1 GenProdlnnov & 0.03 & 0.18 & 0.00 & & 1.00 & 1.00 & & & & & & & & & & & & \\
\hline 2 MktFailure & 0.01 & 0.08 & 0.00 & & 1.00 & -0.02 & & .00 & & & & & & & & & & \\
\hline 3 Months & 1.39 & 0.35 & 0.30 & & 1.78 & -0.02 & -0 & .02 & 1.00 & & & & & & & & & \\
\hline 4 Year_1995 & 0.21 & 0.41 & 0.00 & & 1.00 & -0.01 & & $.05-0$ & 0.19 & 1. & & & & & & & & \\
\hline 5 Year_1996 & 0.20 & 0.40 & 0.00 & & 1.00 & -0.01 & -0 & 0.010 & 0.14 & -0.2 & 1.0 & & & & & & & \\
\hline 6 Year_1997 & 0.20 & 0.40 & 0.00 & & 1.00 & 0.04 & -0 & .02 & $0.35-$ & -0.2 & $26-0.2$ & 1.00 & & & & & & \\
\hline 7 Year_1998 & 0.20 & 0.40 & 0.00 & & 1.00 & -0.05 & -0 & .01 & $0.51-$ & -0.2 & $26-0.2$ & $25-0.25$ & 1.00 & & & & & \\
\hline 8 WIN & 0.54 & 0.50 & 0.00 & & 1.00 & 0.04 & -0 & .04 & 0.04 & $-0 .($ & $02-0.0$ & 0.02 & 0.03 & 1.00 & & & & \\
\hline 9 DesktopPublishing & -0.16 & 0.75 & $5-1.00$ & & $1.00-$ & -0.02 & -0 & $.03-0$ & 0.06 & 0. & 0.0 & $00-0.03$ & $3-0.04$ & $4-0.04$ & 1.00 & & & \\
\hline 10 Spreadsheets & -0.18 & 0.73 & $3-1.00$ & & 1.00 & -0.03 & -0 & $01-0$ & 0.10 & 0.0 & $03-0.0$ & $03-0.04$ & $4-0.05$ & $5-0.07$ & 0.63 & 1.00 & & \\
\hline 11 WordProcessing & -0.16 & 0.75 & $5-1.00$ & & 1.00 & -0.02 & -0 & $.03-0$ & 0.05 & 0.0 & 0.0 & $01-0.03$ & $3-0.04$ & $4-0.03$ & 0.62 & 0.63 & 1.00 & \\
\hline 12 MktDensity & 0.66 & 0.15 & 0.30 & & 1.00 & 0.01 & & .04 & 0.04 & $0 . c_{0}$ & $03-0.0$ & $02-0.01$ & 0.04 & 0.27 & -0.71 & -0.77 & -0.72 & 1.00 \\
\hline 13 MktSize & 3.76 & 0.56 & 2.44 & & 5.01 & 0.03 & -0 & $.04-0$ & 0.28 & 0.0 & $07-0.0$ & $02-0.11$ & $1-0.17$ & 0.62 & 0.29 & 0.26 & 0.41 & -0.07 \\
\hline 14 MktTradeShow & 0.15 & 0.36 & 0.00 & & 1.00 & 0.03 & -0 & .02 & 0.08 & 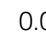 & 0.0 & 0.00 & 0.00 & -0.20 & 0.00 & 0.01 & 0.00 & -0.05 \\
\hline 15 BusinessAge & 2.02 & 0.30 & 0.48 & & 2.31 & -0.02 & -0 & .03 & 0.11 & -0. & 0.0 & 0.05 & 0.10 & -0.03 & 0.28 & 0.25 & 0.35 & -0.35 \\
\hline 16 TotPrevInnov & 2.63 & 1.94 & 0.00 & & 8.00 & -0.03 & -0 & .07 & $0.31-$ & -0. & 0.0 & 0.13 & 0.21 & $1-0.19$ & 0.25 & 0.04 & 0.16 & -0.27 \\
\hline 17 ProductLineSales & 2.50 & 1.21 & 0.00 & & 4.85 & 0.05 & -0 & $.14-0$ & 0.09 & 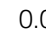 & 0.0 & $02-0.01$ & $1-0.08$ & 0.31 & 0.21 & 0.11 & 0.17 & -0.16 \\
\hline 18 TimeSincelnnov & 17.80 & 15.46 & 1.00 & & 84.00 & 0.02 & & .11 & 0.04 & -0.0 & $02-0.0$ & 0.01 & 0.06 & -0.32 & 0.09 & 0.23 & 0.11 & -0.15 \\
\hline 19 TimeSincelnnov² & 555.61 & 973.13 & 1.00 & $0 \quad 7,056$ & 56.00 & -0.01 & & 12 & 0.03 & 0.0 & $00-0.0$ & 0.01 & 0.06 & -0.31 & 0.08 & 0.26 & 0.09 & -0.15 \\
\hline 20 MktConc & 0.50 & 0.21 & 0.20 & & 1.00 & -0.04 & & .00 & 0.05 & 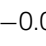 & $08-0.0$ & 0.05 & 0.05 & -0.31 & 0.42 & 0.66 & 0.61 & -0.59 \\
\hline 21 CompetitionInnov & 0.13 & 0.33 & 0.00 & & $1.00-$ & -0.01 & & $.02-0$ & 0.01 & -0.0 & $03-0.0$ & 0.06 & $6-0.04$ & $4 \quad 0.12$ & -0.15 & -0.17 & -0.16 & 0.19 \\
\hline 22 TechOppMP & 0.04 & 0.20 & 0.00 & & 1.00 & 0.06 & & $.01-0$ & 0.06 & 0.0 & $00-0.0$ & 0.10 & $0-0.10$ & -0.05 & 0.00 & 0.00 & 0.00 & -0.02 \\
\hline 23 TechOppOS & 0.06 & 0.24 & 0.00 & & 1.00 & 0.02 & -0 & .02 & $0.01-$ & -0.0 & $04-0.0$ & $03-0.05$ & 0.05 & 0.04 & 0.00 & 0.00 & 0.00 & 0.00 \\
\hline $\begin{array}{l}24 \text { MktConc } \\
* \text { TimeSincelnnov }\end{array}$ & 10.23 & 13.02 & 0.20 & & 81.44 & -0.01 & & .08 & 0.02 & $-0 .($ & $02-0.0$ & 0.00 & 0.07 & -0.33 & 0.16 & 0.42 & 0.25 & -0.27 \\
\hline $\begin{array}{l}25 \text { MktConc } \\
\text { * TimeSincelnnov }{ }^{2}\end{array}$ & 364.00 & 833.86 & 0.20 & $0 \quad 6,79$ & 90.59 & -0.03 & & .09 & 0.02 & 0.0 & $01-0.0$ & $06-0.01$ & 0.06 & $5-0.29$ & 0.10 & 0.35 & 0.14 & -0.19 \\
\hline $\begin{array}{l}26 \text { MktConc } \\
* \text { CompetitionInnov }\end{array}$ & 0.05 & 0.15 & 0.00 & & 0.97 & 0.00 & & $.01-0$ & 0.03 & -0.0 & $04-0.0$ & 0.07 & $7-0.06$ & 0.07 & -0.04 & -0.05 & -0.04 & 0.05 \\
\hline $\begin{array}{l}27 \text { MktConc } \\
* \text { TechOppMP }\end{array}$ & 0.02 & 0.11 & 0.00 & & 0.97 & 0.03 & & $.00-0$ & $0.06-$ & $-0 . c$ & $03-0.0$ & 0.10 & $0-0.10$ & -0.06 & 0.04 & 0.06 & 0.05 & -0.06 \\
\hline $\begin{array}{l}28 \text { MktConc } \\
* \text { TechOppOS }\end{array}$ & 0.03 & 0.13 & 0.00 & & 0.98 & 0.03 & -0 & .02 & 0.01 & 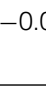 & $06-0.0$ & $04-0.04$ & 0.07 & $7-0.01$ & 0.03 & 0.05 & 0.05 & -0.06 \\
\hline Variable & 13 & 14 & 15 & 16 & 17 & 18 & & 19 & 20 & & 21 & 22 & 23 & 24 & 25 & 26 & 27 & 28 \\
\hline 13 MktSize & 1.00 & & & & & & & & & & & & & & & & & \\
\hline 14 MktTradeShow & -0.14 & 1.00 & & & & & & & & & & & & & & & & \\
\hline 15 BusinessAge & 0.09 & 0.02 & 1.00 & & & & & & & & & & & & & & & \\
\hline 16 TotPrevInnov & -0.17 & 0.06 & 0.41 & 1.00 & & & & & & & & & & & & & & \\
\hline 17 ProductLineSales & 0.40 & -0.06 & 0.34 & 0.36 & 1.00 & & & & & & & & & & & & & \\
\hline 18 TimeSincelnnov & -0.22 & 0.07 & 0.15 & -0.30 & -0.43 & 1.0 & 00 & & & & & & & & & & & \\
\hline 19 TimeSincelnnov $^{2}$ & -0.21 & 0.06 & 0.10 & -0.32 & -0.44 & 0.9 & 94 & 1.00 & & & & & & & & & & \\
\hline 20 MktConc & -0.09 & 0.05 & 0.17 & 0.03 & -0.14 & 0.4 & 41 & 0.42 & 1.0 & 00 & & & & & & & & \\
\hline 21 CompetitionInnov & 0.05 & -0.01 & -0.06 & -0.08 & $3-0.01$ & $1-0.0$ & & -0.05 & -0.1 & & 1.00 & & & & & & & \\
\hline 22 TechOppMP & -0.02 & 0.12 & 0.01 & 0.00 & 0.00 & 0.0 & 02 & 0.01 & 0.0 & 00 & -0.08 & 1.00 & & & & & & \\
\hline 23 TechOppOS & 0.03 & -0.11 & -0.02 & -0.01 & 0.01 & 0.0 & 00 & 0.00 & 0.0 & 01 & -0.04 & -0.05 & 1.00 & & & & & \\
\hline $\begin{array}{l}24 \text { MktConc } \\
\text { *TimeSincelnnov }\end{array}$ & -0.19 & 0.06 & 0.14 & -0.27 & -0.40 & 0.9 & 90 & 0.92 & 0.6 & 66 & -0.09 & 0.01 & 0.01 & 1.00 & & & & \\
\hline $\begin{array}{l}25 \text { MktConc } \\
* \text { TimeSincelnnov }^{2}\end{array}$ & -0.19 & 0.06 & 0.09 & -0.30 & -0.40 & 0.8 & 84 & 0.96 & 0.5 & 52 & -0.07 & 0.00 & 0.00 & 0.95 & 1.00 & & & \\
\hline $\begin{array}{l}26 \text { MktConc } \\
\text { *Competitionlnnov }\end{array}$ & 0.06 & -0.03 & -0.02 & -0.06 & -0.01 & $1-0.0$ & & -0.01 & -0.0 & & 0.90 & -0.07 & -0.04 & -0.01 & -0.01 & 1.00 & & \\
\hline $\begin{array}{l}27 \text { MktConc } \\
\quad * \text { TechOppMP }\end{array}$ & -0.02 & 0.10 & 0.02 & 0.00 & -0.01 & 0.0 & 04 & 0.03 & 0.0 & 08 & -0.07 & 0.91 & -0.05 & 0.05 & 0.04 & -0.07 & 1.00 & \\
\hline $\begin{array}{l}28 \text { MktConc } \\
\text { * TechOppOS }\end{array}$ & 0.00 & -0.10 & 0.01 & 0.00 & 0.00 & 0.0 & 05 & 0.04 & 0.1 & 10 & -0.05 & -0.05 & 0.92 & 0.08 & 0.06 & -0.05 & -0.04 & 1.00 \\
\hline
\end{tabular}


Table 1 (cont'd)

\begin{tabular}{|c|c|}
\hline Variable & Variable description \\
\hline 1 GenProdlnnov & $\begin{array}{l}\text { Generational product innovation ( } 1 \text { if generational product innovation release occurs } \\
\text { during month, } 0 \text { otherwise) }\end{array}$ \\
\hline 2 MktFailure & Market failure ( 1 if product exits from the market, 0 otherwise) \\
\hline 3 Months & Calendar time in months (logged) \\
\hline 4 Year_1995 & Calendar year 1995 ( 1 if observations are during 1995, 0 otherwise) \\
\hline 5 Year_1996 & Calendar year 1996 ( 1 if observations are during 1996, 0 otherwise) \\
\hline 6 Year_1997 & Calendar year 1997 ( 1 if observations are during 1997, 0 otherwise) \\
\hline 7 Year_1998 & Calendar year 1998 ( 1 if observations are during 1998, 0 otherwise) \\
\hline 8 WIN $^{-}$ & Windows operating platform ( 1 if observations are Windows platform, 0 otherwise) \\
\hline 9 DesktopPublishing & Desktop publishing market segment (effect-coded dummy variable) \\
\hline 10 Spreadsheets & Spreadsheets market segment (effect-coded dummy variable) \\
\hline 11 WordProcessing & Word processing market segment (effect-coded dummy variable) \\
\hline 12 MktDensity & Market density (total number of products on the market; lagged one time period and logged) \\
\hline 13 MktSize & Market size (total number of product units sold in the market; lagged one time period and logged) \\
\hline 14 MktTradeShow & Market opportunity event ( 1 if major industry trade show occurs during month, 0 otherwise) \\
\hline 15 BusinessAge & Business line age (number of months since business first released the product in the market; logged) \\
\hline 16 TotPrevInnov & $\begin{array}{l}\text { Cumulative number of previous innovations for product line (count variable that increments by one } \\
\text { after each innovation release) }\end{array}$ \\
\hline 17 ProductLineSales & $\begin{array}{l}\text { Product line sales (total number of product units sold by the organization; lagged one } \\
\text { time period and logged) }\end{array}$ \\
\hline 18 TimeSincelnnov & $\begin{array}{l}\text { Time since previous innovation (elapsed time in months since initial product release or most recent } \\
\text { generational product innovation) }\end{array}$ \\
\hline 19 TimeSincelnnov² & Square of time since previous innovation \\
\hline 20 MktConc & Market concentration (Hirschman-Herfindahl index) \\
\hline 21 Competitionlnnov & $\begin{array}{l}\text { Competition innovation ( } 1 \text { if competing organizations released a generational product innovation, } \\
0 \text { otherwise; lagged one time period) }\end{array}$ \\
\hline 22 TechOppMP & $\begin{array}{l}\text { Technological opportunity event: microprocessor ( } 1 \text { if new class of microprocessor is released } \\
\text { during month, } 0 \text { otherwise) }\end{array}$ \\
\hline 23 TechOppOS & $\begin{array}{l}\text { Technological opportunity event: operating system software ( } 1 \text { if major operating system innovation } \\
\text { is released during month, } 0 \text { otherwise) }\end{array}$ \\
\hline 24 MktConc $*$ TimeSincelnnov & Interaction between market concentration and time since previous innovation \\
\hline 25 MktConc $*$ TimeSincelnnov² & Interaction between market concentration and square of time since previous innovation \\
\hline 26 MktConc $*$ CompetitionInnov & Interaction between market concentration and competition innovation \\
\hline 27 MktConc $*$ TechOppMP & Interaction between market concentration and technological opportunity event: microprocessor \\
\hline 28 MktConc $*$ TechOppOS & Interaction between market concentration and technological opportunity event: operating system so \\
\hline
\end{tabular}

time frame. To identify new classes of microprocessors, we focused on increases in the number of transistors and clock speed. We identified two new microprocessor classes for the IBM-compatible and three new classes for the Macintosh that appeared between 1994 and 1998. For operating system innovations (TechOppOS), Apple supplied the operating system for its Macintosh, and Microsoft was the dominant supplier for the IBMcompatible computer. Based on trade press accounts, we identified three GPIs for the Macintosh operating system. For the IBM-compatible, we identified four GPIs: two focused on corporate and end consumers (Windows 95, Windows 98), whereas two focused on corporate customers (Windows NT 3.5, Windows NT 4.0).

The market concentration (MktConc) measure uses a Hirschman-Herfindhal Index. This measure captures dispersion in unit market share among competing organizations. We calculated the index as the sum of the squared values of products' market share (Curry and George 1983).

Control Variables. The industrial organization economics and organizational ecology literatures suggest control variables at the level of the product line, business unit, and market that may influence the likelihood of innovation. At the product line level, we controlled for innovation experience and size. For innovation experience (TotPrevInnov), which may increase the tendency towards innovation (Amburgey et al. 1993), we employed a count measure. This measure drew on our review of industry trade publications beginning in 1981 and started with the month in which the business released the product line into the market. The innovation experience measure increased by one after each release of a product line GPI. We used sales volume (lagged and logged) to measure the size of the product organization (ProductLineSales), where greater size may provide resources needed for innovation (Cohen 1995); lagging addressed the potential for simultaneity, whereas logging assumed that the effect declined as size increased. At the business unit level, we operationalized organizational age (BusinessAge), which can either facilitate responsiveness or induce inertia (Baum 1999), as the log of the number of months since a business first released the product in the market (irrespective of operating platform). 
Table 2 Generational Product Innovations by Market Segment and Operating Platform

\begin{tabular}{|c|c|c|c|c|c|c|c|c|c|c|}
\hline & \multicolumn{5}{|c|}{ CAD } & \multicolumn{5}{|c|}{ Spreadsheets } \\
\hline & 1994 & 1995 & 1996 & 1997 & 1998 & 1994 & 1995 & 1996 & 1997 & 1998 \\
\hline \multicolumn{11}{|l|}{ Aggregate (Windows, Macintosh) } \\
\hline Number of product lines on market (in January) & 11 & 13 & 12 & 14 & 14 & 9 & 9 & 5 & 6 & 6 \\
\hline Number of product line entrants (during year) & 3 & 2 & 2 & 1 & 2 & 0 & 0 & 1 & 0 & 0 \\
\hline Number of product line exits (during year) & 2 & 2 & 0 & 1 & 2 & 0 & 4 & 0 & 0 & 0 \\
\hline Number of GPI events (during year) & 6 & 5 & 7 & 8 & 4 & 3 & 1 & 2 & 3 & 2 \\
\hline \multicolumn{11}{|l|}{ Windows } \\
\hline Number of product lines on market (in January) & 5 & 8 & 6 & 8 & 8 & 4 & 4 & 3 & 3 & 3 \\
\hline Number of product line entrants (during year) & 2 & $1^{*}$ & 2 & 0 & 2 & 0 & 0 & 0 & 0 & 0 \\
\hline Number of product line exits (over year) & 0 & 2 & 0 & 0 & 1 & 0 & 1 & 0 & 0 & 0 \\
\hline Number of GPI events (during year) & 3 & 3 & 4 & 7 & 3 & 2 & 1 & 2 & 2 & 1 \\
\hline \multicolumn{11}{|l|}{ Macintosh } \\
\hline Number of product lines on market (in January) & 6 & 5 & 6 & 6 & 6 & 5 & 5 & 2 & 3 & 3 \\
\hline Number of product line entrants (during year) & 1 & 1 & 0 & 1 & 0 & 0 & 0 & 1 & 0 & 0 \\
\hline Number of product line exits (over year) & 2 & 0 & 0 & 1 & 1 & 0 & 3 & 0 & 0 & 0 \\
\hline \multirow[t]{3}{*}{ Number of GPI events (during year) } & 3 & 2 & 3 & 1 & 1 & 1 & 0 & 0 & 1 & 1 \\
\hline & \multicolumn{5}{|c|}{ Desktop publishing } & \multicolumn{5}{|c|}{ Word processing } \\
\hline & 1994 & 1995 & 1996 & 1997 & 1998 & 1994 & 1995 & 1996 & 1997 & 1998 \\
\hline \multicolumn{11}{|l|}{ Aggregate (Windows, Macintosh) } \\
\hline Number of product lines on market (in January) & 8 & 8 & 8 & 7 & 7 & 7 & 7 & 8 & 7 & 7 \\
\hline Number of product line entrants (during year) & 0 & 0 & 0 & 0 & 0 & 0 & 1 & 0 & 0 & 0 \\
\hline Number of product line exits (during year) & 0 & 0 & 1 & 0 & 0 & 0 & 0 & 1 & 0 & 0 \\
\hline Number of GPI events (during year) & 3 & 4 & 2 & 5 & 1 & 5 & 3 & 1 & 4 & 0 \\
\hline \multicolumn{11}{|l|}{ Windows } \\
\hline Number of product lines on-market (in January) & 4 & 4 & 4 & 4 & 4 & 4 & 4 & 4 & 4 & 4 \\
\hline Number of product line entrants (during year) & 0 & 0 & 0 & 0 & 0 & 0 & 0 & 0 & 0 & 0 \\
\hline Number of product line exits (over year) & 0 & 0 & 0 & 0 & 0 & 0 & 0 & 0 & 0 & 0 \\
\hline Number of GPI events (during year) & 2 & 2 & 2 & 2 & 1 & 2 & 2 & 1 & 2 & 0 \\
\hline \multicolumn{11}{|l|}{ Macintosh } \\
\hline Number of product lines on-market (in January) & 4 & 4 & 4 & 3 & 3 & 3 & 3 & 4 & 3 & 3 \\
\hline Number of product line entrants (during year) & 0 & 0 & 0 & 0 & 0 & 0 & 1 & 0 & 0 & 0 \\
\hline Number of product line exits (over year) & 0 & 0 & 1 & 0 & 0 & 0 & 0 & 1 & 0 & 0 \\
\hline Number of GPI events (during year) & 1 & 2 & 0 & 3 & 0 & 3 & 1 & 0 & 2 & 0 \\
\hline
\end{tabular}

*The product line entered in January 1995.

Our primary market-level variables addressed operating system platform, market segments, market size, and industry trade shows. Operating system platform captures the potential for differences in technological opportunity across platforms (Scherer 1984). For operating system platform, we included a dummy variable (WIN) to capture the effect of the operating platforms (Windows and Macintosh). Market segments control for the potential for technological opportunity differences across segments (Cohen 1995). We included three dummy variables (DesktopPublishing, Spreadsheets, WordProcessing) to represent the four market segments (computer-aided design, desktop publishing, spreadsheets, and word processing). The dummy variables were effect coded such that a negative effect for DesktopPublishing, Spreadsheets, or WordProcessing represents a lower respective likelihood of releasing a GPI relative to the average likelihood across all four market segments. Market size may influence inno- vation incentives through differences in potential returns associated with the innovation investment (Schmookler 1966). Our market size (MktSize) variable captured the total number of units sold in a given product market, lagged and logged. Industry trade shows are major industry events that concentrate stakeholder attention and may increase incentives to release innovations. The variable (MktTradeShow) is binary: Ones represent the month of occurrence for trade shows and zeros represent the absence of trade shows. Based on the trade press, we identified COMDEX/Fall as the major trade show for Windows-based products. For Macintosh-based products, in addition to COMDEX, we included the Macworld Expo as a major trade show.

Our analyses also included two variables as part of our control for selection bias that might arise from market exits. To illustrate why we employed the selection correction, suppose our objective is to examine the direct effect of market concentration on the likeli- 
hood of releasing a GPI, and we assume that market concentration also influences the likelihood of market exit. By controlling for survival bias, our estimates can properly reflect the marginal effects that market concentration has on both market exit and GPI rather than overattribute its effect on the likelihood of releasing a GPI (see Greene 2000, Heckman 1979). In controlling for the potential selection bias, our first stage analysis included two additional variables that may affect survival but are less likely to affect the likelihood of innovation. Market density (MktDensity) represents the total number of products operating in a market, lagged one time period and logged, drawing from density dependence research in organizational ecology (Hannan and Freeman 1989). Studies of industry evolution, meanwhile, suggest that calendar time (Months), which is also logged, often affects survival (Klepper and Simon 1997).

\section{Models and Analysis}

We used parametric event history analysis for the study, with calendar time as the time axis. We updated all time-dependent variables on a monthly basis. To minimize time aggregation bias (Petersen 1991), we set the selection and innovation events to the midpoint for their months of occurrence. For our focal model, we clustered observations by business line. Utilizing both visual inspection and the AIC criterion, we determined that the most appropriate parametric distribution was the exponential distribution with annual dummy variables. We present the coefficient results in a hazard format. In the hazard format, a positive coefficient reflects an increase in the instantaneous rate of GPI as a measure of the likelihood of innovation.

To control for selection bias that might arise from market exits, we included a lambda estimate in the focal model based on Lee's (1983) generalization of the Heckman (1979) two-stage estimator. We calculated lambda as $\lambda=\left[\phi\left(\Phi^{-1}[1-S(t)]\right)\right] / S(t)$, where $\phi$ is the standard normal density, $\Phi^{-1}$ is the inverse of the standard normal distribution, and $S(t)$ is the survivor function.

\section{Results}

Table 3 presents the results of the first-stage selection model that produced the lambda variable for the secondstage analysis that tested the hypotheses. With thirteen selection events in our data set, we included a moderate number of explanatory variables in the selection model. Market-level variables in the selection model included market density, market size, market concentration, and calendar time. Business age was included as a business level variable, and product line sales and time since previous innovation were variables at the product line level. The likelihood of failure declines with market size, market concentration, calendar time, and product line sales,
Table 3 Estimates for Market Exit

\begin{tabular}{lc}
\hline Explanatory variables & Coeff. \\
\hline Controls & \\
MktSize & $-0.792^{\#}$ \\
MktConc & $-1.942^{*}$ \\
MktDensity & $5.308^{*}$ \\
Months & $-1.062^{*}$ \\
BusinessAge & 0.699 \\
ProductLineSales & $-2.002^{* *}$ \\
TimeSincelnnov & $0.033^{*}$ \\
Intercept & -3.613 \\
Model log-likelihood & $-13.294^{* *}$ \\
\hline
\end{tabular}

Notes. $N=2,041$ organization months, 2,028 on-market observations, 13 market exit events. Exponential distribution for calendar time; coefficients in hazard format (positive coefficient indicates greater likelihood of market exit)

${ }^{*} p<0.05,{ }^{* *} p<0.01,{ }^{\#} p<0.10$ (one-tail tests)

whereas failure increased with market density and time since previous innovation.

Table 4 reports the second-stage analysis, which tests the hypotheses. All models included random effects for the business lines. The table initially adds interaction terms individually and then reports the full set of results in Model 6. Given the directional predictions, we present the results based on one-tail significance tests.

Model 1 included all control variables, as well as the baseline effects of time since previous innovation (TimeSinceInnov, TimeSinceInnov ${ }^{2}$ ), that test Hypothesis 1A. Consistent with Hypothesis 1A, this model found statistical significance for a curvilinear, inverse$\mathrm{U}$ baseline effect for the time since previous innovation $(p<0.01)$.

Models 2 and 6 addressed Hypothesis 1B, which predicts that the relationship between the historical pattern of innovation activity (i.e., time since previous innovation) and the likelihood of releasing a GPI will diminish as market concentration increases. We tested this hypothesis by including interaction terms between market concentration and time since previous innovation (MktConc $*$ TimeSinceInnov) and between market concentration and the square of time since previous innovation $\left(\right.$ MktConc $*$ TimeSinceInnov $\left.{ }^{2}\right)$.

Support for Hypothesis 1B would generate a negative coefficient for MktConc $*$ TimeSinceInnov and a positive coefficient for MktConc $*$ TimeSinceInnov ${ }^{2}$, indicating a flattening of the inverse-U-shaped relationship between time since previous innovation and releasing a new GPI. As expected, Models 2 and 6 report the negative coefficient for the first interaction and a positive coefficient for the second interaction, with moderate significant impact for the interaction with the squared term $(p<0.10)$. Thus, the results provide moderate support for Hypothesis 1B. At the same time, the limited significance of the results suggests that internally driven rhythms of innovation introduction are only partly responsive to competitive conditions. That is, historical patterns sometimes 
Table 4 Estimates for Generational Product Innovation

\begin{tabular}{|c|c|c|c|c|c|c|}
\hline Explanatory variables & $\begin{array}{c}1 \\
\text { Coeff. }\end{array}$ & $\begin{array}{c}2 \\
\text { Coeff. }\end{array}$ & $\begin{array}{c}3 \\
\text { Coeff. }\end{array}$ & $\begin{array}{c}4 \\
\text { Coeff. }\end{array}$ & $\begin{array}{c}5 \\
\text { Coeff. }\end{array}$ & $\begin{array}{c}6 \\
\text { Coeff. }\end{array}$ \\
\hline \multicolumn{7}{|l|}{ Controls } \\
\hline Year_1995 & -0.495 & $-0.518^{\#}$ & $-0.502^{\#}$ & $-0.526^{\#}$ & -0.483 & $-0.521^{\#}$ \\
\hline Year_1996 & -0.412 & -0.379 & -0.402 & -0.419 & -0.390 & -0.336 \\
\hline Year_1997 & 0.393 & 0.463 & 0.389 & 0.389 & 0.385 & 0.465 \\
\hline Year_1998 & $-0.661^{\#}$ & -0.649 & -0.624 & $-0.662^{\#}$ & $-0.692^{\#}$ & -0.617 \\
\hline WIN & 0.306 & 0.325 & 0.320 & 0.294 & 0.349 & 0.374 \\
\hline DesktopPublishing & -0.162 & -0.153 & -0.179 & -0.149 & -0.137 & -0.136 \\
\hline Spreadsheets & 0.099 & 0.063 & 0.117 & 0.118 & 0.092 & 0.088 \\
\hline WordProcessing & -0.072 & -0.046 & -0.080 & -0.058 & -0.034 & -0.009 \\
\hline MktSize & 0.099 & 0.109 & 0.092 & 0.080 & 0.067 & 0.061 \\
\hline MktTradeShow & $0.568^{*}$ & $0.576^{*}$ & $0.604^{*}$ & $0.562^{*}$ & $0.583^{*}$ & $0.628^{*}$ \\
\hline BusinessAge & $-1.554^{* *}$ & $-1.613^{* *}$ & $-1.562^{* *}$ & $-1.576^{* *}$ & $-1.567^{* *}$ & $-1.650^{* *}$ \\
\hline TotPrevinnov & -0.011 & -0.009 & -0.010 & -0.013 & -0.010 & -0.010 \\
\hline ProductLineSales & 0.206 & 0.209 & 0.211 & 0.204 & 0.197 & 0.201 \\
\hline TimeSincelnnov $(\mathrm{H} 1 \mathrm{~A},+)$ & $0.214^{* *}$ & $0.318^{* *}$ & $0.214^{* *}$ & $0.213^{* *}$ & $0.212^{* *}$ & $0.323^{* *}$ \\
\hline TimeSincelnnov ${ }^{2}(H 1 A,-)$ & $-0.004^{* *}$ & $-0.006^{* *}$ & $-0.004^{* *}$ & $-0.004^{* *}$ & $-0.004^{* *}$ & $-0.006^{* *}$ \\
\hline MktConc & -1.516 & -0.202 & $-1.919^{\#}$ & -1.366 & $-2.035^{\#}$ & -0.910 \\
\hline CompetitionInnov & -0.356 & -0.369 & $-1.828^{*}$ & -0.323 & -0.353 & $-1.941^{*}$ \\
\hline TechOppMP & $0.661^{\#}$ & $0.647^{\#}$ & $0.653^{\#}$ & $1.930^{*}$ & $0.659^{\#}$ & 1.430 \\
\hline TechOppOS & 0.552 & 0.556 & $0.569^{\#}$ & 0.548 & -1.411 & -1.546 \\
\hline MktConc $*$ TimeSincelnnov $(\mathrm{H} 1 \mathrm{~B},-)$ & & -0.191 & & & & -0.207 \\
\hline MktConc $*$ TimeSincelnnov $2(\mathrm{H} 1 \mathrm{~B},+)$ & & $0.005^{\#}$ & & & & $0.005^{\#}$ \\
\hline MktConc $*$ CompetitionInnov $(\mathrm{H} 2,+)$ & & & $3.550^{*}$ & & & $3.881^{*}$ \\
\hline MktConc $*$ TechOppMP $(\mathrm{H} 3,+)$ & & & & -3.092 & & -2.023 \\
\hline MktConc $*$ TechOppOS $(\mathrm{H} 3,+)$ & & & & & $3.860^{*}$ & $4.209^{*}$ \\
\hline Lambda & $-4.019^{*}$ & $-4.219^{*}$ & $-4.007^{*}$ & $-4.072^{*}$ & $-4.116^{*}$ & $-4.389^{*}$ \\
\hline Intercept & -2.588 & $-3.269^{\#}$ & -2.406 & -2.496 & -2.181 & -2.684 \\
\hline Theta & 0.000 & 0.000 & 0.000 & 0.000 & 0.000 & 0.000 \\
\hline Model Log-likelihood & $-47.492^{* *}$ & $-46.641^{* *}$ & $-45.912^{* *}$ & $-46.718^{* *}$ & $-45.874^{* *}$ & $-42.653^{* *}$ \\
\hline
\end{tabular}

Notes. $N=2,041$ organization months, 1,972 on-market observations, $69 \mathrm{GPI}$ events. Piecewise-exponential distribution for calendar time (annual dummies); coefficients in hazard format (positive coefficient indicates greater likelihood of release).

${ }^{*} p<0.05,{ }^{* *} p<0.01,{ }^{*} p<0.10$ (one-tail tests).

take on lives of their own that transcend the competitive environment.

Models 3 and 6 examined Hypothesis 2, which predicts that GPI releases will be more responsive to competitors' innovations as market concentration increases. The interaction term (MktConc $*$ CompetitionInnov) tests the hypothesis. A positive coefficient for the interaction would indicate greater event responsiveness. Model 3 (separate introduction) and Model 6 (simultaneous introduction) each report significant positive interaction terms $(p<0.05)$, consistent with Hypothesis 2 .

Models 4, 5, and 6 addressed Hypothesis 3, which predicts that GPI releases will be more responsive to the occurrence of complementary technological opportunity events as market concentration increases. We considered complementary innovations at two foundational levels in the technological system: the microprocessor and the operating system. For microprocessor innovations, the interaction term (MktConc $*$ TechOppMP) was not significant either separately (Model 4) or simultaneously (Model 6). For operating system innovations, however, the MktConc $*$ TechOppOS interaction had a significant effect for both Model 5 and Model $6(p<0.05)$.

To more clearly understand the significance of our interaction results, we conducted a series of simple slope tests (Aiken and West 1991). The tests identify the direction and magnitude of the effects of time since previous innovation as well as innovations by competitors and in complementary technologies at specific levels of market concentration. We conducted external event tests for competitor innovations and operating system innovations, as the two events that significantly interact with market concentration, at three referent levels of market concentration: its mean, one standard deviation above the mean ("high"), and one standard deviation below the mean ("low").

The simple slope tests yield additional insight. For time since previous innovation (H1B), as predicted, Figure 2 reports that the inverse-U-shaped relationship with the likelihood of releasing a GPI flattens as market concentration increased from low to high. Specifically, the coefficient estimates for the square of time since previous innovation diminished from the low level of market 
Figure 2 Effect of Time Since Previous Innovation on Innovation Likelihood at Three Levels of Market Concentration

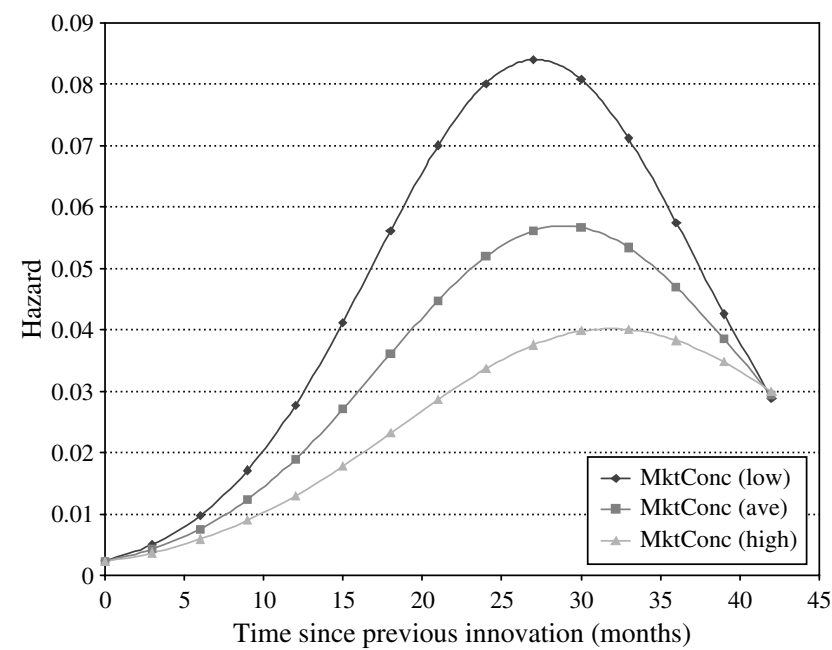

concentration $(b=-0.005$, s.e. $=0.001, p<0.01)$ to the mean level $(b=-0.004$, s.e. $=0.001, p<0.01)$ to the high level of market concentration $(b=-0.002$, s.e. $=0.001, p<0.05)$. For responsiveness to competitor innovations (H2), as expected and shown in Figure 3, we find that businesses are more likely to release GPIs in response to competitor innovations at a high level of market concentration $(b=1.107$, s.e. $=0.733, p<$ $0.10)$. At the mean of market concentration, however, the competitor innovation effect was insignificant $(b=$ 0.203 , s.e. $=0.429$ ); at the low level of concentration, the results indicate that businesses are actually significantly less likely to release an innovation in response to competitors $(b=-0.701$, s.e. $=0.468, p<0.10)$. The differences between responsiveness at high levels of concentration and responsiveness at low levels of concentration are statistically significant. For responsiveness to complementary innovations (H3), we find that the release of an operating system innovation has a positive and significant effect at the high level of concentration $(b=1.760$, s.e. $=0.670, p<0.01)$ and the mean level ( $b=0.779$, s.e. $=0.458, p<0.05)$, whereas the effect was insignificant at the low level of concentration $(b=$ -0.201 , s.e. $=0.685)$. Figure 2 presents the effects of time since previous innovation, and Figure 3 reports the corresponding event effects from the simple slope tests as multipliers on the base rate.

In sum, the results support most predictions, with some intriguing variations. The analyses strongly support Hypothesis 1A and support Hypothesis 1B at a moderate level of statistical significance. The results support Hypothesis 2, with an interesting caveat as discussed in the simple slope tests above. The caveat is that as market concentration increases, businesses are more likely to release GPIs in response to those of competitors (multiplier greater than 1.0), but at low lev-
Figure 3 Slope Test Results for Response to Competitor and Operating System Innovations at Three Levels of Concentration

(a) Multiplier effect of competitor innovation release on the likelihood of generational product innovation

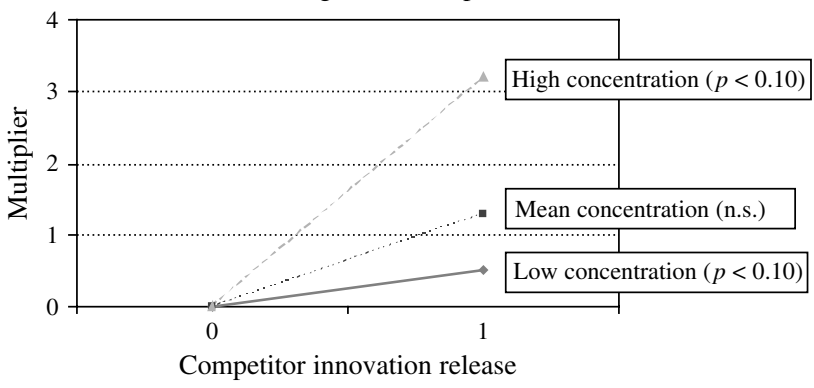

(b) Multiplier effect of operating system release on the likelihood of generational product innovation

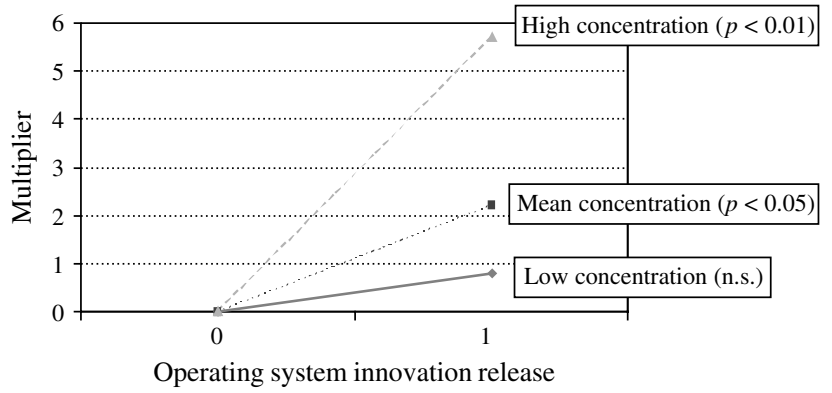

els of concentration, businesses are significantly less likely to do so (multiplier less than 1.0). Thus businesses appear to react to competitor innovations with active avoidance when concentration is low. Perhaps under low concentration (many small-share competitors) it is important to release an innovation at a time when the limited press attention will be available to focus on the innovation exclusively. The results also support Hypothesis 3 for operating system innovations, but we do not find that market concentration influences responsiveness to microprocessor innovations. We address these differences in the discussion section.

\section{Sensitivity Analyses}

We undertook a series of exploratory extensions and sensitivity analyses. We examined additional lags for GPIs by competitors and in complementary technologies, which were not statistically significant. We tested for a curvilinear effect of market concentration on innovation (Scherer and Ross 1990) by adding a quadratic term for concentration but did not find such a relationship. To provide a greater accounting for potential dependence among observations, we employed a conditional risk set approach by replacing the TotPrevInnov variable with a set of dummy variables representing the GPI event that each product line was at risk for throughout the panel, finding materially equivalent results. We added a control variable for product lines owned by corporations that operated in more than one business 
productivity market within our data set (two such corporations in 1994, growing to three in 1998), finding that the variable was insignificant and the hypothesis tests did not change. To determine whether acquisitions of business lines by new corporate owners introduced disruptive effects, we added a dummy variable that indicated the year following when the acquisition takes place, finding that the ownership change coefficient was insignificant and that the hypothesis tests did not change for the focal results.

Cohen's (1995) review suggests that once business size is accounted for, market concentration has little direct effect on innovation. Therefore, we employed an additional model that examined the hypothesized interactions, while controlling for interactions between (a) product line sales and competitor innovation events, (b) product line sales and complementary innovation events, and (c) product line sales and time since previous innovation. In addition, we estimated a probit model that simultaneously estimated the market exit and GPI equations. In both cases (the models accounting for product line sales and those estimated simultaneously), the sensitivity analyses provided equivalent results to the hypothesis tests.

We investigated whether our results were sensitive to the possibility that broader effects like demand growth may directly or indirectly (through interactions with market concentration) influence the likelihood of GPI. To do so, we examined models that added (a) the recent change in market sales, and its interaction with market concentration, (b) the recent change in product line sales and its interaction with market concentration, and (c) the recent change in market concentration. The results did not indicate significant main or interactive effects for the added variables, and the hypothesis results were robust.

We investigated whether the results were sensitive to excluding the 1994 observations based on potential for inadequate representation of the product markets in 1994, given the moderate coverage of the market research data in that year (30\% market share). After excluding the 1994 observations, the analyses yielded the same coefficient directions for the hypothesized interactions, although the interactions were less significant. This difference reflects that fact that there were a large number of GPI events in 1994, as Table 2 reports. We believe that including the 1994 data is appropriate for the analyses, based on our visual inspection of product market share trajectories spanning the 1994 and 1995-1998 data within our data set as well as comparisons of our data with similar data presented in Liebowitz and Margolis (1999).

Finally, we conducted an exploratory investigation of the possibility that the impact of market concentration on the internally and externally driven timing of GPI may be contingent on the relative market position of the product line. We split our sample into three categories of products: those with less than $10 \%$ market share, representing peripheral competitors; $10 \%-40 \%$ share, representing moderate competitors; and more than $40 \%$ share, representing strong competitors. These categories provided a rough balancing of GPI events (18 GPIs by 14 strong competitors, 25 GPIs by 25 moderate competitors, and 26 GPIs by 37 peripheral competitors), along with competitive distinctions that are reasonable for this industry. We then estimated models that tested the hypotheses for each subsample. We stress that these analyses are exploratory owing to the small subsample sizes and number of GPI events by each subcategory of competitors. We can interpret statistical significance only cautiously owing to the small samples. Nonetheless, the patterns reveal potential nuance.

The subsample results were largely consistent with the pooled results for the moderate and strong competitors, although being weaker for peripheral competitors. First, for moderate competitors, the subsample results were directionally consistent with each of the hypotheses, most often with statistical significance. Second, for strong competitors, the subsample results were directionally consistent with H1A, H1B, H2 in response to GPI events by moderate and peripheral competitors, and $\mathrm{H} 3$ in response to complementary operating system introductions, again typically with statistical significance. The subsample results for strong competitors did not support $\mathrm{H} 2$ for introductions by other strong competitors (highly insignificant results), most likely because of the combination of small subsample size and relatively small number of events. The strong competitor results also did not support $\mathrm{H} 3$ for introduction of complementary microprocessor innovations, which is consistent with the pooled results. Third, for peripheral competitors, the results were directionally consistent with H1A, although statistically insignificant. The peripheral competitor results for the remainder of the hypotheses had little or no relationship with the hypotheses and never reached significant levels.

Three summary conclusions emerge from the exploratory analysis of the impact of relative market positions. First, all competitors are at least moderately driven by historical introduction rhythms (H1A), although peripheral competitors appear to be the least bound by historical time-based pacing. Second, as market concentration increases, the influence of historical introduction patterns becomes weaker for moderate and strong competitors (H1B). Third, as market concentration increases, moderate and strong competitors become at least somewhat more responsive to competitor and complementary GPIs. Overall, then, businesses with moderate and strong positions in the market conform most closely to the predictions, whereas peripheral players (those with less than 10\% market share in our analyses) are the least responsive. This pattern is intuitively reasonable, because moderate and strong players 
have the most to gain and lose by their responsiveness or lack thereof.

\section{Discussion}

The objective of this study was to investigate how market concentration, which is a central factor in many theories of innovation, shapes the extent to which GPI strategies reflect innovation events in the external marketplace and historical patterns of innovation. The core finding suggests that GPI strategies typically become less reflective of historical time-based patterns of innovation as market concentration increases and instead increasingly respond both to innovations by competitors and to innovations in complementary technologies.

\section{Implications}

The study has implications for three strands of innovation studies: economics of innovation, competitive rivalry, and the emerging literature on dynamic capabilities.

Economics of Innovation. In examining the timing of GPI introduction, we draw from auction models of nondrastic innovation as the basis for incentives surrounding preemptive innovation. ${ }^{1}$ For nondrastic innovations, which tend to be relatively high certainty $R \& D$ outcomes, pre-innovation market concentration shapes preemption incentives and in turn influences the timing of innovation (Gilbert and Newbery 1982, Reinganum 1989). Whereas traditional auction models and related empirical analyses focus on the direct effect of market concentration on innovation, we extend the competitive threat rationale to examine the effect of concentration on the responsiveness of innovation.

This study relates closely to the game theoretic concept of competitive threats, which stresses that innovation incentives correspond to potential losses associated with current market position (Beath et al. 1995). However, this literature typically has not operationalized and tested the models. Because the stakes surrounding market positions increase in concentrated markets, product innovation behavior tends to be less reflective of historical patterns of innovation and more responsive to competitor and complementary innovation events. Adapting to the release of innovations by competitors helps businesses retain valuable market position, a finding that is consistent with Grabowski and Baxter's (1973) conclusion that $R \& D$ investment patterns are more similar in concentrated markets. For at least some forms of complementary innovations, greater responsiveness helps the businesses preempt or at least match competitors. Thus, our study both clarifies concepts in economic models of innovation and demonstrates empirically how market concentration shapes the responsiveness of GPI to innovations from competitors and in complementary technologies.
Competitive Rivalry. Second, our study offers implications for the competitive rivalry literature in strategic management. Competitive rivalry research draws substantially from Schumpeterian (1934) theories of competitive dynamics and examines innovation introductions as central moves and countermoves (Lee et al. 2000, Young et al. 1996). Extant research argues that as concentration increases, competitive rivalry decreases, based on the logic that greater concentration decreases the incentives to compete aggressively and therefore businesses restrict investment in innovation to achieve higher profitability (Schomburg et al. 1994, Smith et al. 2001). By contrast, our findings indicate that with increases in market concentration, when competitors do introduce innovations, organizations become more responsive in their release of GPIs.

Moreover, the results offer insight into how businesses conform or diverge temporally from competitor innovations. In current research on competitive rivalry, responding is implicitly equated with rapid imitative moves by rivals. In highly concentrated markets, we find evidence of this type of response, which one can refer to as "temporal conformity." In low concentration markets, by contrast, our results suggest an alternative type of reaction-one of "temporal divergence"-in which businesses actively avoid the temporal proximity of rival innovation releases.

Although the temporal divergence implications are only suggestive, we conjecture that this behavior reflects businesses seeking uncontested times of market attention when competing in fragmented market conditions. When facing numerous competitors, businesses can select a temporal position as one means of differentiating their GPI releases relative to competing product innovations. The pattern may also reflect, in part, the complexity of the information environment facing consumers in highly fragmented markets, such that distancing GPI releases from competitor innovations increases the information-processing potential of consumers and as a result impacts purchasing behavior (Jacoby 1984, Simon 1947).

The study also extends the rivalry literature by identifying complementary innovations as potential preemption points. In particular, our unexpected results help clarify the incentives and threats associated with the preemption surrounding complementary innovations. Recall that we found no influence of market concentration on one form of complementary external event, the introduction of microprocessors, in contrast with the significant interaction of concentration with new generations of operating systems. At the same time, though, the main effect results indicate that microprocessor innovations do stimulate GPI by application software businesses.

This difference in the two forms of complementary innovation likely arises because changes in operating systems require greater redesign effort for applications 
software products than do microprocessor innovations because applications software code needs fewer changes in response to microprocessor changes (e.g., increased processor speed). GPI in response to microprocessor innovations requires relatively low investment in redesign; by contrast, responding to operating system innovations requires substantial effort. This difference suggests that application software businesses will be more sensitive to the surrounding competitive implications for GPI investments that are tied to operating system innovations.

This empirical difference has a general implication. Complements that involve high interdependence with the focal product require greater innovative responsiveness. The difference likely arises because the interdependence generates heightened implications for obtaining competitive advantage or maintaining competitive parity.

Dynamic Capabilities. Third, the study contributes to our understanding of the dynamic capabilities that businesses use to change their GPI strategies. Inductive innovation research suggests that businesses tend to follow internally driven strategies (Brown and Eisenhardt 1997). Our results indicate, however, that as concentration increases, businesses increasingly turn to an externally driven GPI strategy. This suggests a dynamic capability to change innovation routines may be a key capability in consolidating markets. Product line managers and businesses that learn to use both internally and externally driven innovation strategies under the appropriate competitive conditions will be best able to renew themselves in the face of GPI-embodied technological competition.

The need to select among internally driven and externally driven strategies involves particularly intriguing forms of dynamic capabilities because the choices reflect what some scholars have referred to as shaping and adapting strategies (Courtney et al. 1997, Courtney 2001). Internally driven innovation timing is a form of a shaping strategy. Shaping strategies aim to influence industry structure and conduct through changes that improve the competitive standing of the company. Companies adopting internally driven innovation strategies seek to systematically improve the competitive standing of their products through independent innovation rather than innovate in response to external events.

By contrast, externally driven innovation is an example of an adapting strategy. Adapting strategies take industry structure and competitive conduct as given and respond - often rapidly - rather than seeking to shape aspects of the industry. Adapting strategies attempt to respond appropriately as external events in the marketplace occur. As shaping and adapting strategies, internally and externally driven innovation strategies stand in strong contrast to traditional positioning strategies that take the market as exogenous or, at best, forecastable.

\section{Limitations}

This research has a significant exploratory component given the limited conceptual and empirical literature regarding influences on the timing of GPI. We seek to establish a reasonable and parsimonious baseline theory and model to facilitate further work in the field. We see the work as a building block for further research in the topic, not as a comprehensive theoretical or empirical edifice. At the same time, as a general limitation, we recognize that there may be other theories and variables relevant to this topic, which beg for investigation moving forward.

We want to highlight some specific limitations. One potential limitation of our study is the treatment of market structure as exogenous. Although we believe it is appropriate to treat market structure as exogenous in the short-term, an interesting avenue for future research lies in examining how GPI strategy might subsequently shape industry structure and dynamics. In turn, from the perspective of competitive rivalry, the literature can be advanced by examining how the responsiveness of GPI to competitive innovations, whether conforming or diverging in timing, and complementary innovations of varying degrees of interdependence affect business performance. Another potential limitation for the generalizability of our findings is the single-industry empirical setting. Although generational innovation is pervasive within industries (Scherer and Ross 1990), it is not clear under what conditions strategies for generational innovation are pursued by businesses. Further, our understanding of GPI strategy could usefully examine longer periods of time and greater spans of the industry life cycle. Future research might also examine how industry structure affects the impact of GPI on performance, relative to more extensive innovation strategies.

\section{Summary Contribution}

Firms face competing pressures to base their innovation timing strategies on internal rhythms and external events. This work suggests that internally driven strategies that reflect historical patterns of innovation predominate when businesses face diffuse competition, but that firms become increasingly responsive to external events as market concentration increases. The core point is that increasing industry concentration raises the stakes surrounding market positions and leads to greater interdependence of innovation strategies in an industry-including interactions both with competitors and with other players in a larger system of complementary products.

\section{Acknowledgments}

The authors are grateful for highly constructive engagement by the reviewers and editors. 


\section{Appendix. Reliability of the Generational Product Innovation Classification}

To examine the reliability of our initial classification system, we developed a set of rules to classify each product release that our information search identified. The rules correspond to the three dimensions: (a) technical improvement relative to the prior release of the product on a platform, (b) the numbering/title convention for the release relative to the prior release, and (c) the pricing schedule for the release (upgrade list price relative to the full list price).

Technical improvement rule: The technical improvement rule classified the release as a GPI if the trade press described the release as containing any new features relative to the prior release. This rule is more likely than our initial classification approach to identify a release as a GPI. As such, its use as an explicit rule provides a conservative check for establishing the reliability of our classification system.

Release numbering rule: The release numbering/title rule was as follows. (1) Classify an innovation as generational if one of the following conditions is true: (a) the release number is greater than or equal to 0.3 relative to the prior release (e.g., WordPerfect 3.0 versus WordPerfect 2.1); (b) the release title includes a year within the title and the prior release did not include a year (e.g., Word 95 versus Word 6.0) or the release title includes a subsequent year from the prior release title (e.g., Word 97 versus Word 95); (c) the release title includes a operating system in the title and the prior release title did not include a operating system (e.g., AutoCAD LT for Windows 95 versus AutoCAD LT 2.0) or the release title includes an operating system in the title and the prior release title included an earlier operating system (e.g., Drafix CAD for Windows 95 versus Drafix CAD for Windows 3.0); or (d) the release title is the same as the prior release but includes a "plus" designation (i.e., MiniCAD+ versus MiniCAD). (2) Do not classify an innovation release as generational if one of the following conditions is true: (a) The release title is the same as the prior release but adds a letter to the title number (e.g., WordPerfect 6.0a versus WordPerfect 6.0) or (b) the release title is the same as the prior release but adds a modification number (e.g., Displaywrite 5, Modification 1 versus Displaywrite 5).

Pricing rule: For the pricing schedule, the rule was to classify a release as a generational release if the upgrade list price was more than $10 \%$ of the list price.

Classification scheme: Using the above explicit rules, we classified each product release along the three dimensions as (1) generational innovation, (2) not a generational innovation, or (3) missing information. The overall classification of the innovation release equaled the majority of nonmissing information across the three dimensions.

Statistics: The explicit set of rules and the initial approach led to identical classifications to the following degree: CAD (95\%), word processing (94\%), desktop publishing (100\%), and spreadsheets (96\%). Data were present for at least two of the three dimensions, and the classification-by-rule results were consistent without the presence of any dissenting classification information to the following degree: CAD (65\%), word processing (65\%), desktop publishing (64\%), and spreadsheets $(80 \%)$. Data were present for two of the three dimensions and the results of the classification-by-rule system were inconclusive (i.e., one dimension toward generational innovation, one dimension toward not generational innovation) to the following degree: $\mathrm{CAD}(0.9 \%)$, word processing $(2.9 \%)$, desktop publishing (0), and spreadsheets (3.7\%). The classificationby-rule approach differed from our initial release classification to the following degree: $\mathrm{CAD}(3.7 \%)$, word processing (2.9\%), desktop publishing (0), and spreadsheets (1.2\%). These small differences reflect the more conservative judgment in our initial classification.

\section{Endnote}

${ }^{1}$ Economic models of innovation timing encompass two basic frameworks: auction (deterministic) models and racing (stochastic) models (Reinganum 1989). Due to differences in conditions, particularly R\&D certainty and innovation type, these models generate contradictory predictions for innovation preemption. Auction models of nondrastic innovation support preemptive innovation by incumbents, whereas racing models of drastic innovation indicate preemptive innovation by challengers. Reinganum (1989) argues that auction models are appropriate for development (product introduction) innovations and that racing models capture basic research (invention) innovations.

\section{References}

Aiken, L. S., S. G. West. 1991. Multiple Regression: Testing and Interpreting Interactions. Sage Publications, Newbury Park, CA.

Amburgey, T. L., D. Kelly, W. P. Barnett. 1993. Resetting the clock: The dynamics of organizational change and failure. Admin. Sci. Quart. 38(1) 51-73.

Argote, L. 1999. Organizational Learning: Creating, Retaining and Transferring Knowledge. Kluwer, Norwell, MA.

Bain, J. S. 1951. Relation of profit rate to industry concentration: American manufacturing, 1936-1940. Quart. J. Econom. 65(3) 293-324.

Baldwin, W. L., J. T. Scott. 1987. Market Structure and Technological Change. Harwood Academic Publishers, London.

Barnett, W. P., G. R. Carroll. 1995. Modeling internal organizational change. Amer. J. Sociol. 21 217-236.

Baum, J. 1999. Organizational ecology. S. R. Clegg, C. Hardy, eds. Studying Organization. Sage Publications, London, 71-108.

Baumol, W. J. 2002. The Free-Market Innovation Machine. Princeton University Press, Princeton, NJ.

Beath, J., Y. Katsoulacos, D. Ulph. 1995. Game-theoretic approaches to the modeling of technological change. P. Stoneman, ed. Handbook of the Economic of Innovation and Technological Change. Blackwell, Oxford, UK, 132-181.

Bettis, R. A., M. A. Hitt. 1995. The new competitive landscape. Strategic Management J. 16 7-19.

Bluedorn, A. C. 2002. The Human Organization of Time. Stanford University Press, Stanford, CA.

Brandenburger, A. J., B. J. Nalebuff. 1997. Co-opetition. Doubleday, New York.

Breschi, S., F. Malerba, L. Orsenigo. 2000. Technological regimes and Schumpeterian patterns of innovation. Econom. J. 110 388-410.

Brown, S. L., K. M. Eisenhardt. 1995. Product development: Past research, present findings, and future directions. Acad. Management Rev. 20(2) 343-378.

Brown, S. L., K. M. Eisenhardt. 1997. The art of continuous change: Linking complexity theory and time-paced evolution in relentlessly shifting organizations. Admin. Sci. Quart. 42 1-34. 
Brown, S. L., K. M. Eisenhardt. 1998. Competing on the Edge: Strategy as Structured Chaos. Harvard Business School Press, Boston.

Campbell-Kelly, M. 2001. Not only Microsoft: The maturing of the personal computer software industry, 1982-1995. Bus. Hist. Rev. 75 103-145.

Cohen, W. M. 1995. Empirical studies of innovative activity. P. Stoneman, ed. Handbook of the Economics of Innovation and Technological Change. Blackwell, Oxford, UK, 182-264.

Courtney, H. 2001. 20/20 Foresight: Crafting Strategy in an Uncertain World. Harvard Business School Press, Boston.

Courtney, H., J. Kirkland, P. Viguerie. 1997. Strategy under uncertainty. Harvard Bus. Rev. 75(6) 66-79.

Curry, B., K. D. George. 1983. Industrial concentration: A survey. J. Indust. Econom. 31(3) 203-255.

Cyert, R. M., J. G. March. 1963. A Behavioral Theory of the Firm. Prentice-Hall, Englewood Cliffs, NJ.

Davies, A. 1996. Innovation in large technical systems: The case of telecommunications. Indust. Corporate Change 5(4) 1143-1180.

Desrochers, P. 2002. Industrial ecology and the rediscovery of interfirm recycling linkages: Historical evidence and policy implications. Indust. Corporate Change 11(5) 1031-1057.

Dosi, G. 1982. Technological paradigms and technological trajectories. Res. Policy 11 147-162.

Dosi, G. 1988. Sources, procedures, and microeconomic effects of innovation. J. Econom. Literature 26 1120-1171.

Dougherty, D. 1992. A practice-centered model of organizational renewal through product innovation. Strategic Management $J$. 13 77-92.

Edmondson, A. C., R. M. Bohmer, G. P. Pisano. 2001. Disrupted routines: Team learning and new technology implementation in hospitals. Admin. Sci. Quart. 46 685-716.

Gersick, C. J. G. 1994. Pacing strategic change: The case of a new venture. Acad. Management J. 37(1) 9-45.

Gilbert, R. J., D. M. G. Newbery. 1982. Preemptive patenting and the persistence of monopoly. Amer. Econom. Rev. 72(3) 514-526.

Grabowski, H. G., N. D. Baxter. 1973. Rivalry in industrial research and development. J. Indust. Econom. 21(2) 209-235.

Greene, W. H. 2000. Econometric Analysis. Prentice Hall, Upper Saddle River, NJ.

Greve, H. 2007. Exploration and exploitation in product innovation. Indust. Corporate Change 16 945-975.

Hannan, M. T., J. Freeman. 1989. Organizational Ecology. Harvard University Press, Cambridge, MA

Hartman, R., D. Teece, W. Mitchell, T. Jorde. 1993. Assessing market power in regimes of rapid technological change. Indust. Corporate Change 2(3) 317-350.

Heckman, J. J. 1979. Sample selection bias as a specification error. Econometrica 47(1) 153-161.

Henderson, R. M., K. B. Clark. 1990. Architectural innovation: The reconfiguration of existing product technologies and the failure of established firms. Admin. Sci. Quart. 35(1) 9-30.

Huff, J. O., A. S. Huff, H. Thomas. 1992. Strategic renewal and the interaction of cumulative stress and inertia. Strategic Management J. 13 55-75.

Jacoby, J. 1984. Perspectives on information overload. J. Consumer Res. 10 432-435.
Kamien, M. I., N. L. Schwartz. 1982. Market Structure and Innovation. Cambridge University Press, Cambridge, UK.

Kelly, D., T. L. Amburgey. 1991. Organizational inertia and momentum: A dynamic model of strategic change. Acad. Management J. 34(3) 591-612.

Klepper, S., K. L. Simon 1997. Technological extinctions of industrial firms: An enquiry into their nature and causes. Indust. Corporate Change 6 379-455.

Klevorick, A. K., R. C. Levin, R. R. Nelson, S. G. Winter. 1995. On the sources and significance of interindustry differences in technological opportunities. Res. Policy. 24 185-205.

Kuhn, T. 1962. The Structure of Scientific Revolutions. University of Chicago Press, Chicago.

Lawless, M. W., P. C. Anderson. 1996. Generational technological change: Effects of innovation and local rivalry on performance. Acad. Management J. 39(5) 1185-1217.

Lee, H., K. G. Smith, C. M. Grimm, A. Schomburg. 2000. Timing, order and durability of new product advantages with imitation. Strategic Management J. 21 23-30.

Lee, L. F. 1983. Generalized econometric models with selectivity. Econometrica 51(2) 507-512.

Liebowitz, S. J., S. E. Margolis. 1999. Winners, Losers and Microsoft. Independent Institute, Oakland, CA.

March, J., H. Simon. 1958. Organizations. John Wiley and Sons, New York

Miller, D., P. H. Friesen. 1980. Momentum and revolution in organizational adaptation. Acad. Management J. 23(4) 591-614.

Nelson, R. R., S. G. Winter. 1982. An Evolutionary Theory of Economic Change. Harvard University Press, Cambridge, MA.

Perrow, C. B. 1970. Organizational Analysis: A Sociological View. Brooks/Cole Publishing Company, Belmont, CA.

Petersen, T. 1991. Time-aggregation bias in continuous-time hazardrate models. Sociol. Methodology 21 263-290.

Reinganum, J. F. 1989. The timing of innovation: research, development and diffusion. R. Schmalensee, R. D. Willig, eds. Handbook of Industrial Organization. Elsevier Science Publishers, New York, 850-908.

Sastry, M. A. 1997. Problems and paradoxes in a model of punctuated organizational change. Admin. Sci. Quart. 42(2) 237-275.

Scherer, F. M. 1984. Innovation and Growth: Schumpeterian Perspectives. MIT Press, Cambridge, MA.

Scherer, F. M. 1992. Schumpeter and plausible capitalism. J. Econom. Literature 30(3) 1416-1433.

Scherer, F. M., D. Ross. 1990. Industrial Market Structure and Economic Performance. Houghton Mifflin, Boston.

Schmookler, J. 1966. Invention and Economic Growth. Harvard University Press, Cambridge, MA.

Schomburg, A., C. M. Grimm, K. G. Smith. 1994. Avoiding new product warfare: The role of industry structure. A. S. Huff, J. E. Dutton, eds. Advances in Strategic Management, Vol. 10B. JAI Press, Greenwich, CT, 145-173.

Schumpeter, J. A. 1934. The Theory of Economic Development. Harvard University Press, Cambridge, MA.

Schumpeter, J. A. 1950. Capitalism, Socialism, and Democracy. Harper \& Brothers Publishers, New York.

Simon, H. A. 1947. Administrative Behavior: A Study of Decisionmaking Processes in Administrative Organizations. Macmillan, Chicago.

Smith, K. G., W. J. Ferrier, H. Ndofor. 2001. Competitive dynamics research: Critique and future directions. M. A. Hitt, R. E. Freeman, J. S. Harrison, eds. The Blackwell Handbook of 
Strategic Management. Blackwell Publishers Ltd., Oxford, UK, 314-361.

Smith, K. G., C. Grimm, M. Gannon, M. J. Chen. 1991. Organizational information processing, competitive responses and performance in the U.S. domestic airline industry. Acad. Management J. 34 60-85.

Somaya, D. 2003. Strategic determinants of decisions not to settle patent litigation. Strategic Management J. 24 17-38.

Stieglitz, N., K. Heine. 2007. Innovations and the role of complementarities in a strategic theory of the firm. Strategic Management J. 28(1) 1-15.
Teece, D. J. 1986. Profiting from technological innovation: Implications for integration, collaboration, licensing and public policy. Res. Policy 15(6) 285-305.

Utterback, J. M. 1996. Mastering the Dynamics of Innovation. Harvard Business School Press, Boston.

Winter, S. 1987. Knowledge and competence as strategic assets. D. J. Teece, ed. The Competitive Challenge: Strategies for Industrial Innovation and Renewal. Harper and Row, New York, 159-184.

Young, G., K. G. Smith, C. M. Grimm. 1996. "Austrian” and industrial organization perspectives on firm- level competitive activity and performance. Organ. Sci. 7(3) 243-254. 